\title{
Arm-in-cage testing of natural human-derived mosquito repellents
}

\author{
James G Logan ${ }^{1,2^{*}}$, Nina M Stanczyk ${ }^{1}$, Ahmed Hassanali ${ }^{3,4}$, Joshua Kemei ${ }^{4}$, Antônio EG Santana ${ }^{5}$, Karlos AL Ribeiro ${ }^{5}$,
} John A Pickett', A Jennifer Mordue (Luntz) ${ }^{2}$

\begin{abstract}
Background: Individual human subjects are differentially attractive to mosquitoes and other biting insects. Previous investigations have demonstrated that this can be attributed partly to enhanced production of natural repellent chemicals by those individuals that attract few mosquitoes in the laboratory. The most important compounds in this respect include three aldehydes, octanal, nonanal and decanal, and two ketones, 6-methyl-5hepten-2-one and geranylacetone [(E)-6,10-dimethylundeca-5,9-dien-2-one]. In olfactometer trials, these compounds interfered with attraction of mosquitoes to a host and consequently show promise as novel mosquito repellents.

Methods: To test whether these chemicals could provide protection against mosquitoes, laboratory repellency trials were carried out to test the chemicals individually at different concentrations and in different mixtures and ratios with three major disease vectors: Anopheles gambiae, Culex quinquefasciatus and Aedes aegypti.

Results: Up to 100\% repellency was achieved depending on the type of repellent compound tested, the concentration and the relative composition of the mixture. The greatest effect was observed by mixing together two compounds, 6-methyl-5-hepten-2-one and geranylacetone in a 1:1 ratio. This mixture exceeded the repellency of DEET when presented at low concentrations. The repellent effect of this mixture was maintained over several hours. Altering the ratio of these compounds significantly affected the behavioural response of the mosquitoes, providing evidence for the ability of mosquitoes to detect and respond to specific mixtures and ratios of natural repellent compounds that are associated with host location.
\end{abstract}

Conclusion: The optimum mixture of 6-methyl-5-hepten-2-one and geranylacetone was a 1:1 ratio and this provided the most effective protection against all species of mosquito tested. With further improvements in formulation, selected blends of these compounds have the potential to be exploited and developed as humanderived novel repellents for personal protection.

\section{Background}

Repellents play an important role in disrupting the interaction between mosquitoes and human beings by reducing bites [1]. Mosquito repellents are mainly accessible to people in developed countries for nuisance insects and to travellers. One of the most widely used and effective insect repellents available is the synthetic compound, $N, N$-diethyl- $m$-toluamide (DEET) and this compound is generally considered to be the "gold standard" repellent, providing long-lasting protection of up to $8 \mathrm{~h}$ from time of application [2]. However, there are

\footnotetext{
* Correspondence: james.logan@bbsrc.ac.uk

'Biological Chemistry Department, Centre for Sustainable Pest and Disease Management, Rothamsted Research, Harpenden, AL5 2JQ, UK

Full list of author information is available at the end of the article
}

some rare reports of severe reactions in people, additionally DEET melts plastics causing spoilage of equipment, such as glasses and mobile phones, and many consumers find the odour and sensation on the skin unpleasant [3]. For these reasons, many potential users prefer natural alternatives such as those based on plant extracts, for example, citronella oil from the Cymbopogon nardus plant and $p$-menthane-3,8- diol (PMD) from lemon eucalyptus (Eucalyptus maculate citriodon), which have good repellent properties [3-6]. The drawback of using plant-based repellents is that many of them are made up of relatively volatile constituents and are generally not effective over long periods of time and as such require frequent reapplication.

\section{Biomed Central}

C 2010 Logan et al; licensee BioMed Central Ltd. This is an Open Access article distributed under the terms of the Creative Commons Attribution License (http://creativecommons.org/licenses/by/2.0), which permits unrestricted use, distribution, and reproduction in any medium, provided the original work is properly cited. 
A most important use of repellents in developing countries could be a role in reducing malaria, as well as other vector-borne diseases including dengue and West Nile Virus all vectored by different mosquito species $[2,3,7]$. Indeed, there is recent evidence to show that repellents can significantly reduce malaria incidence by the prevention of biting of Anopheline mosquitoes by the use of topical treatments with repellents or by protection with repellent impregnated bednets $[8,9]$. However, most repellents are currently expensive, difficult to distribute and difficult to incorporate into local traditions and practices. The indigenous poor are not likely to purchase commercial repellent formulations and are more likely to rely on cheaper alternatives which are less effective [10,11]. In developing countries (particularly sub-Saharan Africa) alternative methods such as insecticide-treated bed nets (ITNs) and indoor residual spraying are thought to be the most appropriate method of control. However, in some regions, mosquito populations are less susceptible to these control methods because of insecticide resistance [12,13]. Additionally, alterations in behavioural patterns cause some mosquitoes to feed earlier and more frequently outdoors than previously observed [14]. This increases the contact between mosquitoes and human beings and renders ITNs less effective $[11,15]$. In some cases this is thought to have occurred due to selection pressure from the use of ITNs themselves. In such situations, where mosquitoes feed earlier and more readily outdoors, repellents could play a supplementary yet significant role in controlling arthropod-borne diseases [11].

Although many repellents are available, there is a need to discover a new generation of compounds that overcome the limitations of the repellents described above [1]. A repellent that is safe, cheap, and has no or little odour is desirable and this will ultimately be one which contains the lowest possible amount of active ingredients. Although a repellent for Anopheles gambiae mosquitoes is desirable for protection against malaria it would be highly advantageous to have one which is also effective against other mosquito species including Aedes and Culex species.

Recently, several compounds have been identified from the skin volatile profiles of human subjects that elicited little or no attractant response from Aedes aegypti mosquitoes in laboratory trials. These compounds are likely to be involved in the natural 'avoidance' of certain human beings by mosquitoes and, therefore, have the potential to be exploited as new, natural repellents [16]. Olfactometer experiments with $A e$. aegypti showed that octanal, nonanal, decanal, 6-methyl5-hepten-2-one and geranylacetone significantly 'interfered' with host-location [16]. Although it was suggested that the compounds had a repellent effect, the olfactometer used in the experiments did not allow appropriate testing of the compounds as repellents nor were field trials with volunteers a possibility at that time. However, recent field trials with Culicoides impunctatus midges demonstrated that 6-methyl-5-hepten-2-one, geranylacetone, decanal and octanal, on their own and in mixtures, reduced midge landings on the forearms of human volunteers when applied topically [17]. These studies suggest that the compounds could also be used as repellents against mosquitoes.

This study was designed to test the efficacy of five novel human-derived putative repellent compounds at different concentrations and in selected mixtures comprising different combinations and ratios against the malaria vector, An. gambiae s.s., and two other medically important mosquito species, Culex quinquefasciatus and Ae. aegypti.

\section{Methods}

\section{Chemicals}

6-Methyl-5-hepten-2-one (99\%), nonanal (95\%), decanal (95\%), geranylacetone $[(E)-6,10$-dimethylundeca-5,9dien-2-one] (96\%) and DEET (97\%) were obtained from Sigma-Aldrich, UK. Octanal (99\%) was obtained from Fluka, UK.

\section{Arm-in-cage repellency trials Single compounds}

6-Methyl-5-hepten-2-one, octanal, nonanal, decanal and geranylacetone were tested for repellency against $A n$. gambiae s.s., Cx. quinquefasciatus and Ae. aegypti mosquitoes using established methods, based on a WHO protocol [18]. Anopheles gambiae s.s. and Cx. quinquefasciatus mosquitoes were laboratory-reared at icipe, Kenya. Aedes aegypti mosquitoes were laboratory reared at UFAL, Brazil. Female mosquitoes (mated, 5-7 days post emergence) that had not previously had a blood meal and that had been starved for $18 \mathrm{~h}$ but previously fed on $6 \%$ glucose solution were used in experiments. Fresh cages $(50 \times 50 \times 50 \mathrm{~cm})$, with 50 female mosquitoes in each, were used for each treatment within a testing session. Six volunteers with no or little allergic reaction to bites were selected for the trials. Experiments involving An. gambiae s.s. and Cx. quinquefasciatus were done in Kenya, and experiments involving Ae. aegypti were done in Brazil.

Repellent compounds in acetone (ethanol for Ae. aegypti) solutions $(0.5 \mathrm{ml})$ were applied to a volunteer's forearm from the elbow to the wrist and the hand was covered with a Nitrile glove. Acetone (or ethanol) alone $(0.5 \mathrm{ml})$ served as a control on the other arm. The control arm was inserted into a cage and the number of landings was recorded over $3 \mathrm{~min}$. Then the treatment arm was inserted into the same cage and the number of 
landings recorded in the same way. Control and treatment arms were interchanged between experimental sessions to eliminate bias.

Each compound was tested at several concentrations, starting with the lowest dose: $0.0001 \%, 0.001 \%, 0.01 \%$, $0.1 \%, 1 \%$ and $10 \%$ resulting in dosages of $0.83 \mathrm{ng} / \mathrm{cm}^{2}$ to $0.083 \mathrm{mg} / \mathrm{cm}^{2}$ (corresponding to $500 \mathrm{ng}$ to $50 \mathrm{mg}$ per forearm; calculated using an estimated forearm skin area from elbow to wrist to be $600 \mathrm{~cm}^{2}$ ) [3]. Repellency data were expressed as protective efficacy (PE) and were calculated using the formula $\mathrm{PE}=$ (mean number of mosquitoes landed on control arm - mean number of mosquitoes landed on test arm/mean number of mosquitoes landed on control arm).

\section{Unformulated and formulated mixtures}

Three mixtures were tested against all three mosquito species at the same concentrations as above for single compounds and comprised: Mixture 1, 1:1:1:1:1 of 6methyl-5-hepten-2-one:octanal:nonanal:decanal:geranylacetone, Mixture 2, 1:3:1:0.5:0.5 of 6-methyl-5-hepten-2one:octanal:nonanal:decanal:geranylacetone (the ratios in this mixture represent the average 'unattractive' volunteer in a previous study [16], and Mixture 3, 1:1 of 6methyl-5-hepten-2-one:geranylacetone. Due to a trend showing Ae. aegypti to respond more to the aldehydes than the ketones, a fourth mixture (Mixture 4) was tested with this species only. It comprised 1:1:1 octanal: nonanal:decanal.

Mixture 1 and Mixture 3 were then incorporated into a formulation which comprised emulsifying wax NF (National Formulary Emulsifying Wax), Petroleum jelly and liquid paraffin in a 1.2:2.8:1 ratio. These formulated mixtures were tested immediately after application using the above methodology and were repeated 2, 4, 6 and 8 hours after application to give PE over time for $A n$. gambiae s.s., Cx. quinquefasciatus and every hour for 8 hours for Ae. aegypti. For these experiments the control comprised an arm treated with formulation only.

Unformulated mixtures in different ratios with An gambiae

The most effective repellent compounds in this study (6-methyl-5-hepten-2-one and geranylacetone) were tested together in mixtures of different ratios using the methods above at several doses $(0.001 \%, 0.01 \%, 0.1 \%, 1 \%$ and $10 \%)$. The ratios tested were 1:0 (100\%:0\%), 4:1 (80\%:20\%), 3:1 (75\%:25\%), 3:2 (60\%:40\%), 5:4 (55\%:45\%), $1: 1 \quad(50 \%: 50 \%), \quad 4: 5 \quad(45 \%: 55 \%), \quad 2: 3 \quad(40 \%: 60 \%) \quad 1: 3$ (25\%:75\%), 1:4 (20\%:80\%) and 0:1 (0\%:100\%) 6-methyl-5hepten-2-one:geranylacetone. These tests were carried out with $A n$. gambiae mosquitoes only.

\section{Statistical analysis}

Repellency data were analysed using a generalized linear model (GLM) with binomial error and logit link (logistic regression). The back-transformed treatment means were used to calculate PE and the PE standard error. The back transformed treatment means were used for treatment comparisons using least significant differences between all treatments $(\mathrm{p}<0.05)$. To demonstrate synergism, a generalized linear mixed model was used to test whether the effects of the 1:1 ratio differed significantly from the sum of the effects of 1:0 plus the effects of the 0:1 ratio for each concentration. Statistical analyses were performed using GenStat Version 11 (Payne 2008).

\section{Ethics}

This study was approved by the Grampian Research Ethics Committee (07/S0801/51). Human-bait (arm-incage) repellency experiments at ICIPE were approved by the Ethical Review Committee at the Kenya Medical Research Institute (Protocol KEMRI/RES/7/3/1).

\section{Results}

Arm-in-cage repellency trials

\section{Single compounds/An. gambiae}

All five human-derived compounds relating to low attractancy $[16,17]$ and tested against $A n$. gambiae gave dose-dependent repellency, with the maximum repellency observed for all compounds at $10 \%$, the top dose tested. One hundred percent repellency was recorded for geranylacetone at $10 \%$. DEET gave better repellency than the single compounds with $100 \%$ repellency at $1 \%$ and $10 \%$ doses (Table 1).

\section{Single compounds/Cx. quinquefasciatus}

For $C x$. quinquefasciatus dose-dependent repellency was also observed, with the greatest repellency for each compound at $10 \%$. Unexpectedly, octanal and nonanal had a strong attractive effect at low concentrations, and gave some repellency at high concentrations. Decanal, $6 \mathrm{MHO}$, geranylacetone and DEET gave $100 \%$ repellency but only at a concentration of $10 \%$. Decanal alone gave the greatest repellency (91\%) at the lower concentration of $1 \%$ (Table 1).

\section{Single compounds/Ae. aegypti}

Dose-dependent repellency was observed for Ae. aegypti and, for each compound, the greatest repellency was achieved with the $10 \%$ concentration. Overall, DEET gave the greatest efficacy with $100 \%$ repellency achieved at all concentrations except $0.001 \%$ which gave $88.7 \%$ repellency. With this species the most effective single compounds were nonanal and decanal. At the $10 \%$ concentration decanal and nonanal gave $\sim 90 \%$ protection which was greater than 6-methyl-5-hepten-2-one and geranylacetone which gave $\sim 70 \%$ repellency (Table 1 ).

\section{Unformulated mixtures/An. gambiae}

For $A n$. gambiae the greatest repellency was given by Mixture 3, which achieved $100 \%$ repellency at $1 \%$ and $10 \%$ and by Mixture 1 and 2 which achieved $100 \%$ 
Table 1 Protective Efficacy (\%) of five human-derived semiochemicals and DEET tested at different concentrations in arm-in-cage experiments

\begin{tabular}{|c|c|c|c|c|c|c|}
\hline \multirow[b]{2}{*}{ Conc. (\%) } & \multicolumn{6}{|c|}{ Mean \% PE (+S.E.) } \\
\hline & DEET & Octanal & Nonanal & Decanal & $6 \mathrm{MHO}$ & GA \\
\hline \multicolumn{7}{|c|}{ Anopheles gambiae } \\
\hline 0.0001 & - & $-17.4( \pm 3.0)^{C^{C *}}$ & $-21.4( \pm 2.9)^{e^{* *}}$ & $-13.4( \pm 4.3)^{\mathrm{e} *}$ & $0.9( \pm 3.9)^{c}$ & - \\
\hline 0.001 & $6.2( \pm 1.7)^{d}$ & $-9.9( \pm 1.5)^{c}$ & $-12.7( \pm 2.2)^{\mathrm{de}}$ & $5.9( \pm 4.5)^{\mathrm{de}}$ & $1.6( \pm 11.2)^{c}$ & $7.3( \pm 9.5)^{b}$ \\
\hline 0.01 & $20.7( \pm 6.4)^{C *}$ & $5.1( \pm 5.2)^{b}$ & $-6.3( \pm 2.8)^{d}$ & $9( \pm 6)^{d}$ & $19.2( \pm 5.5)^{\mathrm{bc} *}$ & $11.2( \pm 12.9)^{b}$ \\
\hline 0.1 & $83.8( \pm 3.9)^{b_{*}}$ & $11.3( \pm 7.2)^{\mathrm{b}}$ & $5.7( \pm 4.0)^{c}$ & $30.1( \pm 7.7)^{\complement_{*}}$ & $34.1( \pm 6.6)^{b_{*}}$ & $30.1( \pm 11)^{b_{*}}$ \\
\hline 1 & $100( \pm 0)^{a *}$ & $31.7( \pm 5.6)^{\mathrm{a} *}$ & $37.4( \pm 5.9)^{\mathrm{b}_{*}}$ & $55.9( \pm 6)^{b *}$ & $35.7( \pm 8.7)^{\mathrm{b} *}$ & $77( \pm 5.9)^{\mathrm{a} *}$ \\
\hline 10 & $100( \pm 0)^{\mathrm{a} *}$ & $44.2( \pm 5.4)^{a_{*}}$ & $73.8( \pm 4.7)^{a_{*}}$ & $97.2( \pm 1.4)^{a_{*}}$ & $74.75( \pm 6.1)^{a_{*}}$ & $100( \pm 0)^{a *}$ \\
\hline \multicolumn{7}{|c|}{ Culex quinquefasciatus } \\
\hline 0.0001 & - & $-47.3( \pm 5.1)^{d *}$ & $-45.9( \pm 6.2)^{e *}$ & $-24.1( \pm 8)^{d *}$ & $8( \pm 1.8)^{d}$ & $4.8( \pm 2.4)^{d}$ \\
\hline 0.001 & $7.6( \pm 1.8)^{c}$ & $-38.2( \pm 4.1)^{d_{*}}$ & $-27.7( \pm 4.9)^{d_{*}}$ & $-23.5( \pm 4.5)^{\mathrm{d} *}$ & $12.7( \pm 2.1)^{d_{*}}$ & $10( \pm 1.6)^{d_{*}}$ \\
\hline 0.01 & $12( \pm 1.7)^{c *}$ & $-22.8( \pm 5.5)^{c_{*}^{*}}$ & $-16( \pm 3.5)^{\mathrm{cd} *}$ & $5.7( \pm 2.5)^{c}$ & $21.8( \pm 4.9)^{\mathrm{C*}}$ & $23.7( \pm 4.5)^{c *}$ \\
\hline 0.1 & $76.9( \pm 5.4)^{b_{*}}$ & $-13.5( \pm 5.8)^{b_{*}}$ & $-9.6( \pm 3)^{c}$ & $37.3( \pm 10)^{b_{*}}$ & $30.1( \pm 4.1)^{c_{*}}$ & $33.2( \pm 4.5)^{c *}$ \\
\hline 1 & $98.2( \pm 1.1)^{\mathrm{a} *}$ & $-1.6( \pm 3.2)^{a}$ & $23.0( \pm 8.2)^{b_{*}}$ & $91.3( \pm 2.7)^{\mathrm{a} *}$ & $49.7( \pm 2.9)^{\mathrm{b} *}$ & $84.1( \pm 4.2)^{\mathrm{b*}}$ \\
\hline 10 & $100( \pm 0)^{\mathrm{a} *}$ & $9.8( \pm 1.9)^{\mathrm{a}}$ & $78.3( \pm 2.5)^{a_{*}}$ & $100( \pm 0)^{a_{*}}$ & $100( \pm 0)^{a_{*}}$ & $100( \pm 0)^{a *}$ \\
\hline \multicolumn{7}{|c|}{ Aedes aegypti } \\
\hline 0.001 & $88.7( \pm 1.9)^{b *}$ & $-11.9( \pm 4.6)^{c}$ & $-21.4( \pm 5.9)^{c}$ & $-18.8( \pm 5.5)^{d}$ & $-27.4( \pm 6.3)^{d}$ & $11.7( \pm 4.5)^{d}$ \\
\hline 0.01 & $100( \pm 0)^{\mathrm{a} *}$ & $-10.4( \pm 4.3)^{c}$ & $45.5( \pm 7.04)^{b}$ & $-9.4( \pm 4.1)^{d}$ & $-18.9( \pm 5.5)^{d}$ & $32.8( \pm 6.6)^{c}$ \\
\hline 0.1 & $100( \pm 0)^{\mathrm{a} *}$ & $24.4( \pm 6.1)^{b_{*}}$ & $53.6( \pm 7.1)^{\mathrm{b}}$ & $18.9( \pm 5.5)^{c}$ & $12.3( \pm 4.6)^{c}$ & $41.1( \pm 6.9)^{b c}$ \\
\hline 1 & $100( \pm 0)^{\mathrm{a} *}$ & $31.9( \pm 6.6)^{\mathrm{b} *}$ & $68.8( \pm 6.6)^{b}$ & $53( \pm 7.1)^{b}$ & $39.6( \pm 6.9)^{b}$ & $46.7( \pm 7.05)^{b}$ \\
\hline 10 & $100( \pm 0)^{\mathrm{a} *}$ & $53.3( \pm 7.1)^{\mathrm{a} *}$ & $89.3( \pm 4.37)^{\mathrm{a}}$ & $90( \pm 4.3)^{\mathrm{a}}$ & $71.7( \pm 6.4)^{\mathrm{a}}$ & $73.3( \pm 6.25)^{\mathrm{a}}$ \\
\hline
\end{tabular}

6MHO 6-methyl-5-hepten-2-one

GA geranylacetone

Means followed by different letters are significantly different from each other $(P<0.05)$

P.E. $=$ protective efficacy $(\%$ control mean $-\%$ test mean $/ \%$ control mean)

*Significantly different from the control (untreated arm) $(P<0.05)$

repellency at $10 \%$. At the lower concentration $(0.1 \%)$ $87 \%$ repellency was recorded. At the same concentration, DEET gave $83 \%$ repellency. At concentration $0.01 \%$, Mixture 3 gave $79.4 \%$ repellency, whereas DEET at $0.01 \%$ gave only $20.7 \%$ repellency (Table 2 ).

\section{Unformulated mixtures/Cx. quinquefasciatus}

Mixture 1 and Mixture 3 gave 100\% repellency at 10\% for Cx. quinquefasciatus. At lower concentrations, Mixture 1 gave greater repellency than Mixture 3 with $84 \%$ and $77 \%$ repellency achieved respectively at a concentration of $1 \%$ (Table 2).

\section{Unformulated mixtures/Ae. aegypti}

All of the mixtures tested against Ae. aegypti gave dosedependent repellency, with the highest repellency for each mixture observed at $10 \%$. Mixture 3 gave the greatest repellency overall $(78 \%)$ at the $10 \%$ concentration. Mixture 1 gave significant repellency at $0.1 \%, 1 \%$ and $10 \%$ doses, but the greatest repellency (37.3\%) was at a concentration of $10 \%$. Mixture 1 gave significant a maximum repellency of $37.3 \%$; Mixture 2, which was prepared to represent an unattractive human individual in a ratio of $1: 3: 1: 0.5: 0.5$, gave $44.1 \%$ repellency and
Mixture 4 achieved $53.6 \%$ repellency, all at a concentrations of $10 \%$.

\section{Formulated mixtures/An. gambiae}

For An. gambiae both formulated mixtures gave 100\% repellency at the start of the experiments (i.e. time zero). Around 90\% repellency was achieved after 2 hours with Mixture 1 and this decreased over time to give $12 \%$ efficacy after 8 hours, which was not significantly different from the formulation control. Greater repellency was observed for Mixture 3 with $98 \%$ repellency recorded after 2 hours. Repellency then decreased to $64 \%$ after 4 hours and to $35 \%$ after 8 hours. All time periods, with the exception of 8 hours for Mixture 1, were significantly different from the formulation control. DEET gave the best repellency by maintaining $100 \%$ protection for up to 6 hours and $94 \%$ after 8 hours (Table 3).

\section{Formulated mixtures/Cx. quinquefasciatus}

With $C x$. quinquefasciatus both formulated mixtures gave $100 \%$ repellency at the start of the experiment, and this decreased slightly to $89 \%$ for Mixture 1 and to $99 \%$ for Mixture 3 after 2 hours. After 8 hours, the 
Table 2 Protective Efficacy (\%) of three mixtures of human-derived semiochemicals at different concentrations in armin-cage experiments

\begin{tabular}{|c|c|c|c|c|}
\hline \multirow[b]{2}{*}{ Concentration (\%) } & \multicolumn{3}{|c|}{ Mean \% P.E. ( \pm S.E.) } & \multirow[b]{2}{*}{ Mixture 4} \\
\hline & Mixture 1 & Mixture 2 & Mixture 3 & \\
\hline \multicolumn{5}{|l|}{ Anopheles gambiae } \\
\hline 0.0001 & - & - & $9.4( \pm 2.3)^{d}$ & - \\
\hline 0.001 & $9.2( \pm 1.8)^{\mathrm{e}}$ & $-3.5( \pm 6.4)^{d}$ & $24.4( \pm 5.1)^{\mathrm{c*}}$ & - \\
\hline 0.01 & $16.9( \pm 3.5)^{d *}$ & $16.5( \pm 5.1)^{\mathrm{C*}}$ & $79.4( \pm 3.7)^{\mathrm{b} *}$ & - \\
\hline 0.1 & $44.6( \pm 3.5)^{c_{*}}$ & $26.9( \pm 3.7)^{c_{*}}$ & $87.1( \pm 3.1)^{b_{*}}$ & - \\
\hline 1 & $94.1( \pm 1.1)^{b_{*}}$ & $59.5( \pm 3.1)^{\mathrm{b} *}$ & $100( \pm 0)^{a *}$ & - \\
\hline 10 & $100( \pm 0)^{\mathrm{a} *}$ & $100( \pm 0)^{\mathrm{a}_{*}}$ & $100( \pm 0)^{\mathrm{a} *}$ & - \\
\hline \multicolumn{5}{|l|}{ Culex quinquefasciatus } \\
\hline 0.001 & $9.6( \pm 3.5)^{d}$ & - & $11.3( \pm 1.9)^{\mathrm{d} *}$ & - \\
\hline 0.01 & $20.82( \pm 4.9)^{\mathrm{cd} *}$ & - & $20.8( \pm 2.3)^{d_{*}}$ & - \\
\hline 0.1 & $33.46( \pm 3.8)^{c *}$ & - & $55.6( \pm 5.8)^{c_{*}^{*}}$ & - \\
\hline 1 & $84.1( \pm 7)^{b_{*}}$ & - & $77( \pm 4.5)^{b_{*}}$ & - \\
\hline 10 & $100( \pm 0)^{\mathrm{a} *}$ & - & $100( \pm 0)^{\mathrm{a} *}$ & - \\
\hline \multicolumn{5}{|l|}{ Aedes aegypti } \\
\hline 0.001 & $-4.5( \pm 8.3)^{d}$ & $20( \pm 8.3)^{b_{*}}$ & $17.7( \pm 8.3)^{C_{*}}$ & $10.6( \pm 8.3)^{C_{*}}$ \\
\hline 0.01 & $6.4( \pm 4.9)^{c}$ & $25( \pm 8.7)^{\mathrm{b} *}$ & $8.8( \pm 5.7)^{c}$ & $16.3( \pm 7.4)^{\mathrm{C*}}$ \\
\hline 0.1 & $19( \pm 7.9)^{b_{*}}$ & $25.8( \pm 8.8)^{b_{*}}$ & $26.5( \pm 8.8)^{c_{*}}$ & $12.7( \pm 6.7)^{c_{*}}$ \\
\hline 1 & $30( \pm 9.2)^{\mathrm{a} *}$ & $40.8( \pm 9.8)^{a *}$ & $48.7( \pm 9.9)^{b_{*}}$ & $29.1( \pm 9.1)^{\mathrm{b} *}$ \\
\hline 10 & $37.3( \pm 9.7)^{\mathrm{a} *}$ & $44.1( \pm 9.9)^{a *}$ & $77.9( \pm 8.3)^{a *}$ & $53.6( \pm 9.9)^{\mathrm{a} *}$ \\
\hline
\end{tabular}

Mixture 1 = 1:1:1:1:1 6-methyl-5-hepten-2-one:octanal:nonanal:decanal:geranylacetone

Mixture $2=$ 1:3:1:0.5:0.5 6-methyl-5-hepten-2-one:octanal:nonanal:decanal:geranylacetone

Mixture $3=1: 16$-methyl-5-hepten-2-one:geranylacetone

Mixture $4=1: 1: 1$ octanal: nonanal: decanal

Means followed by different letters are significantly different from each other $(P<0.05)$

P.E. = protective efficacy $(\%$ control mean $-\%$ test mean $/ \%$ control mean $)$

*Significantly different from the control (untreated arm) $(P<0.05)$

repellency given by Mixture 1 had decreased to $20 \%$. However, for Mixture 3, repellency was maintained at a greater level, decreasing only to $80 \%$ after 4 hours, $60 \%$ after 6 hours and $45 \%$ after 8 hours. DEET gave 100\% repellency up until 6 hours and this decreased to $93 \%$ after 8 hours (Table 3).

Formulated mixtures/Ae. aegypti

For Ae. aegypti the formulated Mixture 1 gave around $45 \%$ repellency at the start of the experiment and maintained this repellency for 1 hour. It then decreased rapidly to $13 \%$ after 2 hours and beyond this time gave no significant protection. Mixture 3 gave greater repellency $(60 \%)$ at the start of the experiment. This reduced to $43.6 \%$ after 1 hour, $30 \%$ after 2 hours and $21 \%$ after 3 hours. Beyond this time, no significant repellency was achieved (Table 3).

Unformulated mixtures in different ratios with Ae. aegypti All ratios of Mixture 3 (6-methyl-5-hepten-2-one with geranylacetone) provided significant repellency at $10 \%$. However, the mixtures that contained ratios with relatively more 6-methyl-5-hepten-2-one than geranylacetone were more effective (achieving between $99 \%$ and 100\% repellency) than those that contained more geranylacetone than 6-methyl-5-hepten-2-one (achieving between 93\% and $97 \%$ repellency) (Figure 1). This effect was more marked at the intermediate concentrations. For two concentrations, $0.01 \%$ and $0.1 \%$, the $1: 1$ ratio was more effective than the sum of effects of individual ratios 0:1 and 1:0, with statistical significance $\mathrm{p}=0.0257$ and $\mathrm{p}<0.0001$, respectively. At the lower doses, there appeared to be little difference between the different ratios although the 1:1 mixture gave the greatest protection which was significantly greater than the two compounds on their own (Figure 1).

\section{Discussion}

\section{Single compounds}

The three aldehydes tested in this study provided varying degrees of protection. Decanal provided the greatest repellency at the highest concentration (10\%) for all three mosquito species tested (Table 1). Similarly, Logan et al. [16] demonstrated that decanal reduced Ae. aegypti flight 
Table 3 Protective Efficacy (\%) of two formulated mixtures of human-derived semiochemicals and DEET (10\% concentration) in arm-in-cage experiments

\begin{tabular}{|c|c|c|c|}
\hline Time post application (hrs) & DEET & Mixture 1 & Mixture 3 \\
\hline \multicolumn{4}{|l|}{ Anopheles gambiae } \\
\hline 0 & $100( \pm 0)^{a_{*}}$ & $100( \pm 0)^{a_{*}}$ & $100( \pm 0)^{\mathrm{a} *}$ \\
\hline 2 & $100( \pm 0)^{\mathrm{a} *}$ & $89.4( \pm 3.7)^{\mathrm{a} *}$ & $98.5( \pm 1.51)^{\mathrm{a} *}$ \\
\hline 4 & $100( \pm 0)^{\mathrm{a} *}$ & $54.9( \pm 4.5)^{\mathrm{b} *}$ & $64.3( \pm 6.15)^{\mathrm{b} *}$ \\
\hline 6 & $100( \pm 0)^{\mathrm{a} *}$ & $32.1( \pm 5.6)^{\mathrm{C*}}$ & $38.8( \pm 4.31)^{c *}$ \\
\hline 8 & $94.4( \pm 1)^{\mathrm{b} *}$ & $12.5( \pm 2.1)^{d}$ & $30.8( \pm 6.96)^{c_{*}}$ \\
\hline \multicolumn{4}{|l|}{ Culex quinquefasciatus } \\
\hline 0 & $100( \pm 0)^{\mathrm{a} *}$ & $100( \pm 0)^{a *}$ & $100( \pm 0)^{\mathrm{a} *}$ \\
\hline 2 & $100( \pm 0)^{a_{*}}$ & $89( \pm 4.2)^{\mathrm{a}_{*}}$ & $98.6( \pm 1.43)^{a *}$ \\
\hline 4 & $100( \pm 0)^{a *}$ & $56.2( \pm 4.4)^{\mathrm{b} *}$ & $80( \pm 1.7)^{\mathrm{b} *}$ \\
\hline 6 & $100( \pm 0)^{a_{*}}$ & $28.5( \pm 5.2)^{c_{*}}$ & $60.9( \pm 3.1)^{c_{*}}$ \\
\hline 8 & $93.3( \pm 4.08)^{\mathrm{b} *}$ & $19.8( \pm 3.2)^{c *}$ & $45.8( \pm 4.1)^{\mathrm{d} *}$ \\
\hline \multicolumn{4}{|l|}{ Aedes aegypti } \\
\hline 0 & $100( \pm 0)^{\mathrm{a} *}$ & $46.5( \pm 9.9)^{a_{*}}$ & $60( \pm 9.8)^{a_{*}}$ \\
\hline 1 & $100( \pm 0)^{\mathrm{a} *}$ & $46.1( \pm 9.9)^{a *}$ & $43.6( \pm 9.9)^{\mathrm{ab} *}$ \\
\hline 2 & $100( \pm 0)^{a_{*}}$ & $13.8( \pm 6.9)^{b_{*}}$ & $30.9( \pm 9.2)^{b c *}$ \\
\hline 3 & $100( \pm 0)^{a *}$ & $-8.6( \pm 5.6)^{b}$ & $21.1( \pm 5.6)^{\mathrm{cd} *}$ \\
\hline 4 & $100( \pm 0)^{a_{*}}$ & $17.2( \pm 7.6)^{b c}$ & $11.3( \pm 6.3)^{d}$ \\
\hline 5 & $100( \pm 0)^{\mathrm{a} *}$ & $10.3( \pm 6.09)^{b c}$ & $7.04( \pm 5.1)^{d}$ \\
\hline 6 & $100( \pm 0)^{a *}$ & $-15.5( \pm 7.24)^{c}$ & $-16.9( \pm 7.2)^{\mathrm{e}}$ \\
\hline 7 & $97( \pm 1.95)^{b_{*}}$ & $1.7( \pm 2.6)^{c}$ & $-2.8( \pm 2.6)^{e}$ \\
\hline 8 & $96.1( \pm 1.94)^{b_{*}}$ & $-8.6( \pm 5.6)^{c}$ & $-2.9( \pm 3.3)^{\mathrm{e}}$ \\
\hline
\end{tabular}

Mixture 1 = 1:1:1:1:1 6-methyl-5-hepten-2-one:octanal:nonanal:decanal:geranylacetone

Mixture 3 = 1:1 6-methyl-5-hepten-2-one:geranylacetone

Means followed by different letters are significantly different from each other $(P<0.05)$

P.E. = protective efficacy (\% formulation control mean - \% test mean $\%$ formulation control mean)

*Significantly different from the control (formulation-treated arm) $(P<0.05)$

activity to levels equal to a clean air control - significantly more than octanal and nonanal. Octanal provided significant repellency but only for Ae. aegypti and An. gambiae. Douglas et al. $[19,20]$ also demonstrated that octanal was repellent against Ae. aegypti mosquitoes. In their study they identified octanal (and other aldehydes) from seabird odour and suggested that aldehydes are produced by birds as natural protection against ectoparasites [20]. Whilst this might be true for some arthropods, Ae. aegypti tend to feed on mammals (mainly humans in urban areas) and would not normally be attracted to birds. Some Culex species, including $C x$. quinquefasciatus, are known to be ornithophilic and so it might be expected that their response to the aldehydes would be different from that of Ae. aegypti. When octanal was tested against $C x$. quinquefasciatus, it provided no protection at all from biting. In fact, the presence of octanal (and the other aldehydes), particularly at the low concentrations, significantly increased the attractiveness of the volunteer's arms during the tests. Indeed other studies have demonstrated that nonanal elicits electrophysiological and "attractive" behavioural responses in Cx. quinquefasciatus mosquitoes [21-23]. Although one study demonstrated that Ae. aegypti are attracted to odour from bird feathers [24], Ae. aegypti and $A n$. gambiae are normally anthropophilic and, therefore, the aldehydes tested in this study could form part of a kairomonal avian blend for bird-feeding mosquitoes, but may signal that the host is 'inappropriate' for non-bird feeding insects like Ae. aegypti and An. gambiae mosquitoes. The aldehydes may hold promise as attractants which could be used in traps (particularly for $C x$. quinquefasciatus), although this requires further investigation. As a topically applied repellent, the lower homologue and more volatile octanal is not a good candidate, however, nonanal and decanal at high concentrations show somewhat greater promise. But these compounds were tested over a short time period only.

All three mosquito species responded to the two ketones in a dose-dependent manner and both compounds gave significant protection at high concentrations (this was particularly the case for 6-methyl-5-hepten-2one). Similarly, Logan et al [16] showed that these 

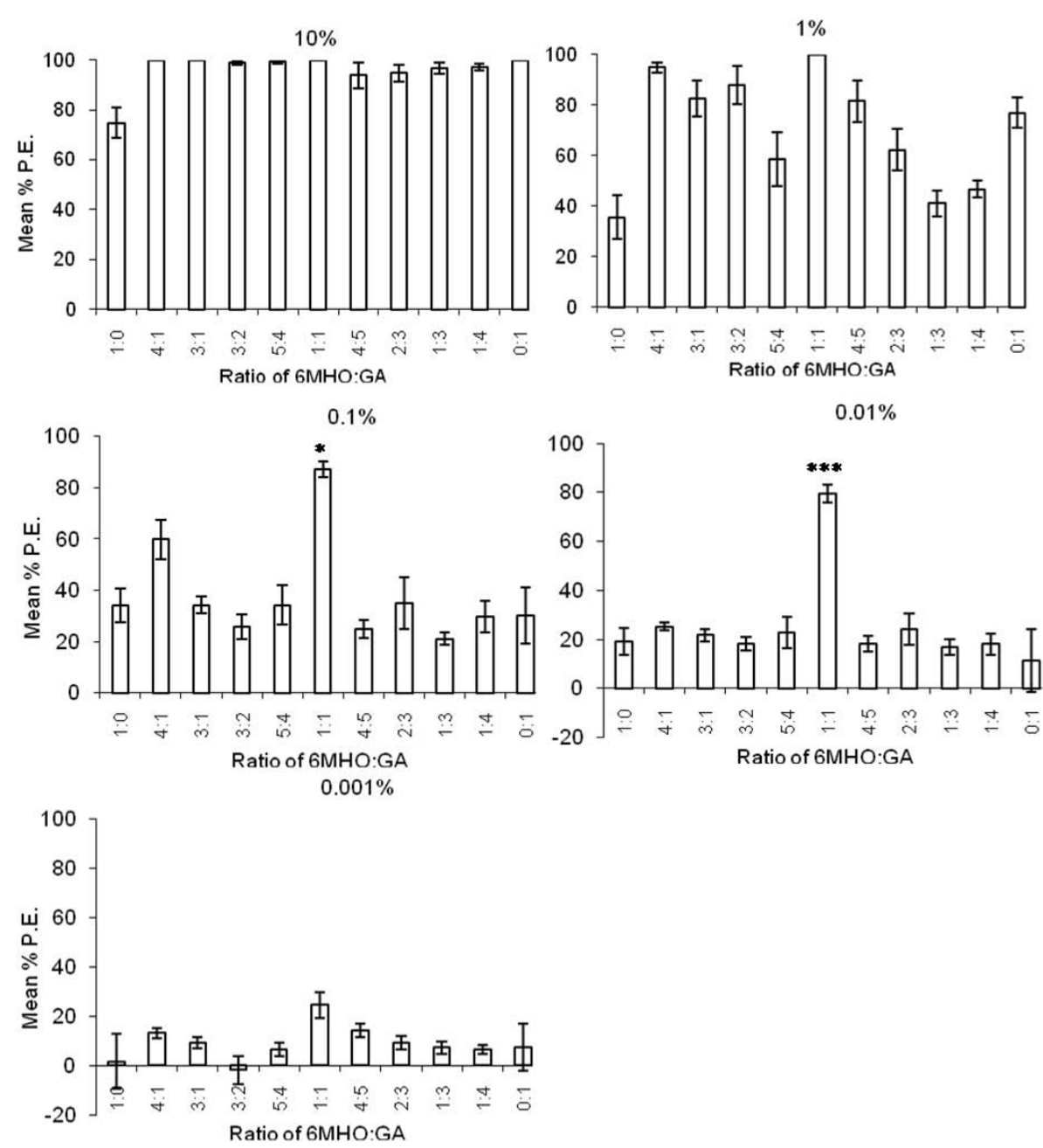

Figure 1 Protective efficacy (\% PE) of several mixtures of 6-methyl-5-hepten-2-one and geranylacetone in different ratios and tested at different concentrations in arm-in-cage experiments with An. gambiae mosquitoes. Asterix indicate significant differences between 6methyl-5-hepten-2-one (6MHO) alone and Mixture $3(1: 1,6 \mathrm{MHO}: \mathrm{GA})$ and between geranylacetone $(\mathrm{GA})$ alone and Mixture $3(1: 1,6 \mathrm{MHO}: \mathrm{GA})\left({ }^{*} \mathrm{p}<\right.$ $\left.0.05 ;{ }^{* *} p<0.01 ;{ }^{* *} p<0.001\right)$.

compounds significantly affected Ae. aegypti flight activity and relative attraction in an olfactometer. Both compounds have also been shown to reduce the attraction of An. gambiae in response to a mixture of ammonia, lactic acid and carboxylic acids in an olfactometer [25]. In the field, 6-methyl-5-hepten-2-one is also known to reduce the numbers of the cattle flies, Musca autumnalis (Diptera: Muscidae) and Haematobia irritans (Diptera: Muscidae) landing on cattle [26]. Although geranylacetone gave the greatest repellency overall for two of the mosquito species tested, $100 \%$ repellency was only achieved with the $10 \%$ dose.

\section{Unformulated mixtures and ratios}

When all five compounds were combined into a 1:1:1:1:1 ratio (Mixture 1), 100\% repellency was achieved with the $10 \%$ dose with An. gambiae and Cx. quinquefasciatus (37.3\% for Ae. aegypti at 10\%), but there did not appear to be any greater effect of this combination compared with the single compounds (Table 2). Similarly, when the compounds were tested against An. gambiae in a mixture (1:3:1:0.5:0.5, Mixture 2), which was designed to replicate the ratios produced naturally by a relatively "unattractive" human [16] there was very little additive effect. In fact, this ratio gave lower protection than Mixture 1. However, when the aldehydes were removed to give Mixture 3 (1:1 6-Methyl-5-hepten-2one:geranylacetone), a striking effect was observed, particularly at low concentrations. For example, with $A n$. gambiae $87 \%$ repellency was recorded for the $0.1 \%$ dose that exceeded (although not significantly) DEET at the same concentration, which gave $83 \%$ repellency. At an 
even lower concentration (0.01\%), Mixture 3 maintained a high level of repellency (80\%), whereas DEET gave only $20 \%$ repellency. This was a clear demonstration of synergism, as the mixture provided better protection than the sum of the repellency achieved by the single compounds at the same concentration. For example, at the $0.1 \%$ dose for An. gambiae, 6-methyl-5-hepten-2one alone gave $34.1 \%$, geranylacetone alone gave $30.1 \%$ repellency and Mixture 3 gave $87.1 \%$ repellency. At the $0.01 \%$ dose, 6 -methyl-5-hepten-2-one alone gave $19.2 \%$, geranylacetone alone gave $11.2 \%$ repellency and Mixture 3 gave $79.4 \%$ repellency. This is the first demonstration whereby adding two natural, host-derived compounds together can create a synergistic effect to produce a more potent repellent (as shown in Figure 1). Because of this result, the relative amounts of each compound in Mixture 3 were altered to determine whether a different ratio would provide better protection against An. gambiae than Mixture 3 (1:1 ratio).

As expected all ratios of Mixture 3 provided excellent protection at $10 \%$, however, the effect of altering the ratios was apparent at the lower concentrations. The mixtures containing a relatively greater proportion of 6 methyl-5-hepten-2-one than geranylacetone were more effective than those that contained a greater proportion of geranylacetone than 6-methyl-5-hepten-2-one (Figure $1)$. In the Logan et al. study [16], these compounds were found to occur in "unattractive" people on average in a 1:0.7 (6-methyl-5-hepten-2-one:geranylacetone) ratio and in "attractive" people in a ratio of $1: 2$ [16]. Therefore, the 1:1 ratio tested in this study (Mixture 3) more closely resembled the ratio found in an "unattractive" individual than in an "attractive" person. At the lower doses, there appeared to be little difference between the ratios, although Mixture 3 (1:1) always gave the greatest protection overall and thus shows promise as a repellent for all three species tested in this study.

\section{Formulated mixtures}

For most repellents that contain volatile compounds a slow release formulation is required to provide controlled release over time. The loss of efficacy of repellents over time is usually due to evaporative loss, dermal absorption, and abrasive loss or through the effects of perspiration and washing $[1,27,28]$. In this study, a basic wax-formulation was used to provide slow release of compounds. For all species, repellency decreased over time, but for An. gambiae and Cx. quinquefasciatus a high level of repellency was maintained up to 2-4 hours (Table 3). Although 6-methyl-5-hepten-2-one and geranylacetone seem to have a potent effect on mosquitoes (as demonstrated by the large level of protection provided by low concentrations) their efficacy is not long lived and does not last as long as DEET, which can remain effective for up to 8 hours. Recently, Moore et al [11] demonstrated efficacy of a low-cost repellent containing PMD and lemongrass oil (with fixatives) for up to 6 hours, which was more effective than DEET, against Anopheles darlingi in Peru. They suggest this would be a suitable repellent for malaria-endemic countries. However, even compounds like DEET and PMD, that have low volatilities in comparison to the compounds in this study, are only effective over time at or above doses of $10 \%$. Due to the high volatility of the compounds in this study they evaporated from the skin more quickly than DEET. New advances in formulation technologies could be exploited to develop appropriate formulations that achieve slower release rates over time and this should result in the volatile compounds achieving efficacy over time that matches or exceeds that of DEET. A period of longer than 6-8 hours protection is desired. Further work is underway to develop a formulation for topically-applied preparations using these human-derived repellents.

The two ketones tested here have the potential to be used as active ingredients in new topical repellent formulations. In initial studies, the chemicals had a significant repellent effect in small quantities which suggests that, providing a suitable formulation is developed, a repellent could be created that is both odourless with little or no irritation to the skin and with no untoward side effects - characteristics that are consumer pleasing, yet not met by the current repellents on the market [29]. Additionally, 6-methyl-5-hepten-2-one and geranylacetone are acceptable food additives and are, therefore, unlikely to cause any toxicological complications (JEFCA website, 2005). The compounds could also be impregnated into clothing or onto bednets, the latter of which could be combined with insecticide treatments. However, to be effective and economically viable (especially in developing countries), these chemicals must be obtained with relative ease and low cost.

Plants often offer alternative cheap and renewable resources for semiochemical production, especially in resource-poor afflicted countries. This has been demonstrated for the $C x$. quinquefasciatus oviposition pheromone (5R,6S)-6-acetoxy-5-hexadecanolide, where the precursor (Z)-5-hexadecenoic acid can be obtained from seed oil of a renewable plant resource, Kochia scoparia (Chenopodiaceae) [30-33]. Using this method, the pheromone can be obtained at a cost of $\$ 3$ per gram which compares favourably with conventional synthetic methods which cost \$15 per gram [31]. Similarly, the sandfly pheromone, (S)-9-methylgermacrene-B, can be synthesized from germacrone, a major component of Geranium macrorrhizum (Geraniaceae) essential oil [34]. Since 6-methyl-5-hepten-2-one and geranylacetone are 
commonly produced by plants a similar process could be used to obtain the compounds in this study and further work is underway to discover suitable plant sources of the two monoterpenes [35].

\section{Conclusion}

Two compounds, 6-methyl-5-hepten-2-one and geranylacetone, when combined in a 1:1 mixture show promise as a topical repellent that is effective over a short time period. Further work with formulation technologies that will allow a slower release of the compounds is ongoing and should provide a repellent that is effective over several hours. Although the high volatility is a disadvantage when developing a topical repellent, it could be advantageous if the compounds affect mosquito behaviour some distance from the host. Indeed, the compounds identified here have already been shown to affect flight activity and attraction towards host odour in an olfactometer [16]. A "spatial repellent", released from a dispenser, would be a major advantage and could result in the development of a new class of mosquito repellents that provide protection within a given area without the need for topical application. Further work is underway to assess 6-methyl-5-hepten-2-one and geranylacetone as spatial repellents.

\section{Acknowledgements}

We thank NESTech for funding and give special thanks to the volunteers and assistants who participated in the study. Elisa Losa is thanked for assistance with statistical analysis. Rothamsted receives grant-aided support from the BBSRC.

\section{Author details \\ ${ }^{1}$ Biological Chemistry Department, Centre for Sustainable Pest and Disease Management, Rothamsted Research, Harpenden, AL5 2JQ, UK. ${ }^{2}$ School of Biological Sciences, University of Aberdeen, Tillydrone Avenue, Aberdeen AB24 2TZ, UK. ${ }^{3}$ Chemistry Department, Kenyatta University, P.O. Box 43844- 00100, Nairobi, Kenya. ${ }^{4}$ Behavioural and Chemical Ecology Department, International Centre for Insect Physiology and Ecology, P.O. Box 30772, GPO 00100, Nairobi, Kenya. ${ }^{5}$ Laboratório de Ecologia Química, Departamento de} Química, Universidade Federal de Alagoas 57072-970, Maceió, Alagoas, Brasil.

\section{Authors' contributions}

$J G L, A J M, A H$ and JAP contributed to design of the study, conceived the protocol and provided funding. The study was coordinated by JGL. NS and JGL performed the data analysis and interpretation. NS, KR, JGL, AH contributed in the study design and in the implementation of the research. JGL, AJM, NS contributed to manuscript drafting. All authors read and approved the final manuscript.

\section{Competing interests}

The authors declare that they have no competing interests.

Received: 11 May 2010 Accepted: 20 August 2010

Published: 20 August 2010

\section{References}

1. Katritzky AR, Wang ZQ, Slavov S, Tsikolia M, Dobchev D, Akhmedov NG, Hall CD, Bernier UR, Clark GG, Linthicum KJ: Synthesis and bioassay of improved mosquito repellents predicted from chemical structure. Proc Natl Acad Sci USA 2008, 105:7359-7364.
2. Fradin MS: Mosquitoes and mosquito repellents: A clinician's guide. Ann Int Med 1998, 128:931-940.

3. Trongtokit Y, Rongsriyam Y, Komalamisra N, Apiwathnasorn C: Comparative repellency of 38 essential oils against mosquito bites. Phytother Res 2005, 19:303-309.

4. Curtis CF, Lines JD, ljumba J, Callaghan A, Hill N, Karimzad MA: The relative efficacy of repellents against mosquito vectors of disease. Med Vet Entomol 1987, 1:109-119.

5. Trigg JK, Hill N: Laboratory evaluation of a eucalyptus-based repellent against four biting arthropods. Phytother Res 1996, 10:313-316.

6. Trigg JK: Evaluation of a eucalyptus-based repellent against Anopheles spp in Tanzania. J Am Mosquito Contr 1996, 12:243-246.

7. Curtis C: Personal protection methods against vectors of disease. Rev Med Vet Entomol 1992, 8:543-553.

8. Rowland M, Downey G, Rab A, Freeman T, Mohammad N, Rehman H, Durrani N, Reyburn H, Curtis C, Lines J, Fayaz M: DEET mosquito repellent provides personal protection against malaria: a household randomized trial in an Afghan refugee camp in Pakistan. Trop Med Int Health 2004, 9:335-342

9. Hill N, Lenglet A, Arnez AM, Carneiro I: Plant based insect repellent and insecticide treated bed nets to protect against malaria in areas of early evening biting vectors: double blind randomised placebo controlled clinical trial in the Bolivian Amazon. BMJ 2007, 335:1023-1025.

10. Worrall $E$, Basu $S$, Hanson $K$ : Is malaria a disease of poverty? A review of the literature. Trop Med Int Health 2005, 10:1047-1059.

11. Moore SJ, Darling ST, Sihuincha M, Padilla N, Devine GJ: A low-cost repellent for malaria vectors in the Americas: results of two field trials in Guatemala and Peru. Malar J 2007, 6:101

12. N'Guessan R, Corbel V, Akogbeto M, Rowland M: Reduced efficacy of insecticide-treated nets and indoor residual spraying for malaria control in pyrethroid resistance area, Benin. Emerg Infect Dis 2007, 13:199-206.

13. Protopopoff N, Verhaeghen K, Van Bortel W, Roelants P, Marcotty T, Baza D, D'Alessandro U, Coosemans M: A significant increase in kdr in Anopheles gambiae is associated with an intensive vector control intervention in Burundi highlands. Trop Med Int Health 2008, 13:1479-1487.

14. Bayoh MN, Mathias DK, Odiere MR, Mutuku FM, Kamau L, Gimnig JE, Vulule JM, Hawley WA, Hamel MJ, Walker ED: Anopheles gambiae: historical population decline associated with regional distribution of insecticide-treated bed nets in western Nyanza Province, Kenya. Malar J 2010, 9:62.

15. Alexander N, Rodriguez M, Perez L, Caicedo JC, Cruz J, Prieto G, Arroyo JA Cotacio MC, Suarez M, De la Hoz F, Hall AJ: Case-control study of mosquito nets against malaria in the Amazon region of Colombia. Am J Trop Med Hyg 2005, 73:140-148.

16. Logan JG, Birkett MA, Clark SJ, Powers S, Seal NJ, Wadhams LJ, Mordue AJ Pickett JA: Identification of human-derived volatile chemicals that interfere with attraction of Aedes aegypti mosquitoes. J Chem Ecol 2008, 34:308-322.

17. Logan JG, Seal NJ, Cook JI, Stanczyk NM, Birkett MA, Clark SJ, Gezan SA, Wadhams LJ, Pickett JA, Mordue J: Identification of Human-Derived Volatile Chemicals That Interfere With Attraction of the Scottish Biting Midge and Their Potential Use as Repellents. J Med Entomol 2009, 46:208-219.

18. Omolo MO, Okinyo D, Ndiege 1O, Lwande W, Hassanali A: Repellency of essential oils of some Kenyan plants against Anopheles gambiae. Phytochemistry 2004, 65:2797-2802.

19. Douglas HD, Co JE, Jones TH, Conner WE, Day JF: Chemical odorant of colonial seabird repels mosquitoes. J Med Entomol 2005, 42:647-651.

20. Douglas HD, Co JE, Jones TH, Conner WE: Heteropteran chemical repellents identified in the citrus odor of a seabird (crested auklet Aethia cristatella): evolutionary convergence in chemical ecology. Naturwissenschaften 2001, 88:330-332.

21. Agresti C, DUrso D, Levi G: Reversible inhibitory effects of interferongamma and tumour necrosis factor-alpha on oligodendroglial lineage cell proliferation and differentiation in vitro. European Journal of Neuroscience 1996, 8:1106-1116.

22. Syed Z, Leal WS: Acute olfactory response of Culex mosquitoes to a human- and bird-derived attractant. Proc Natl Acad Sci USA 2009, 106:18803-18808.

23. Puri SN, Mendki MJ, Sukumaran D, Ganesan K, Prakash S, Sekhar K: Electroantennogram and Behavioral responses of Culex quinquefasciatus 
(Diptera: Culicidae) females to chemicals found in human skin emanations. J Med Entomol 2006, 43:207-213.

24. Allan SA, Bernier UR, Kline DL: Laboratory evaluation of avian odors for mosquito (Diptera: culicidae) attraction. J Med Entomol 2006, 43:225-231.

25. Qiu YT: Sensory and behavioural responses of the malaria mosquito Anopheles gambiae to human odours Wageningen: University of Wageningen 2005

26. Birkett MA, Agelopoulos N, Jensen MV, Jespersen JB, Pickett JA, Prijs HJ, Thomas G, Trapman JJ, Wadhams $L$, Woodcock CM: The role of volatile semiochemicals in mediating host location and selection by nuisance and disease-transmitting cattle flies. Med Vet Entomol 2004, 18:313-322.

27. Rueda LM, Rutledge LC, Gupta RK: Effect of skin abrasions on the efficacy of the repellent deft against Aedes aegypti. J Am Mosquito Contr 1998, 14:178-182.

28. Dethier VG: Chemical insect attractants and repellents Philadelphia: Blakiston 1947.

29. Mark S, Fradin MD: Mosquitoes and mosquito repellents: A clinician's guide. Ann Int Med 1998, 59:595-596.

30. Olagbemiro TO, Birkett MA, Mordue AJ, Pickett JA: Laboratory and field responses of the mosquito, Culex quinquefasciatus, to plant-derived Culex spp. oviposition pheromone and the oviposition cue skatole. Chem Ecol 2004, 30:965-976.

31. Olagbemiro TO, Birkett MA, Mordue AJ, Pickett JA: Production of (5R,6S)-6acetoxy-5-hexadecanolide, the mosquito oviposition pheromone, from the seed oil of the summer cypress plant, Kochia scoparia (Chenopodiaceae). Journal of Agricultural and Food Chemistry 1999, 47:3411-3415.

32. Laurence BR, Pickett JA: "Erythro-6-Acetoxy-5-Hexadecanolide, the major component of a mosquito oviposition attractant pheromone. Journal of the Chemical Society-Chemical Communications 1982, 59-60.

33. Logan JG, Birkett MA: Semiochemicals for biting fly control: their identification and exploitation. Pest Manag Sci 2007, 63:647-657.

34. Hooper AM, Farcet JB, Mulholland NP, Pickett JA: Synthesis of 9methylgermacrene B, racemate of the sex pheromone of Lutzomyia longipalpis (Lapinha), from the renewable resource, Geranium macrorrhizum essential oil. Green Chemistry 2006, 8:513-515.

35. Fruekilde $P$, Hjorth J, Jensen NR, Kotzias D, Larsen B: Ozonolysis at vegetation surfaces: A source of acetone, 4-oxopentanal, 6-methyl-5hepten-2-one, and geranyl acetone in the troposphere. Atmos Environ 1998, 32:1893-1902.

doi:10.1186/1475-2875-9-239

Cite this article as: Logan et al: Arm-in-cage testing of natural humanderived mosquito repellents. Malaria Journal 2010 9:239.

\section{Submit your next manuscript to BioMed Central and take full advantage of:}

- Convenient online submission

- Thorough peer review

- No space constraints or color figure charges

- Immediate publication on acceptance

- Inclusion in PubMed, CAS, Scopus and Google Scholar

- Research which is freely available for redistribution

Submit your manuscript at www.biomedcentral.com/submit
Biomed Central 